\title{
In Vivo D-Glucose Absorption in the Developing Rat Small Intestine
}

\author{
M. K. YOUNOSZAI ${ }^{(24)}$ AND A. LYNCH \\ Pediatric Gastrointestinal Laboratory, Department of Pediatrics, College of Medicine, \\ The University of Iowa, Iowa City, Iowa, USA
}

\section{Extract}

Solutions containing $D$-glucose $(1-20 \mathrm{mg} / \mathrm{ml})$ were perfused in situ through the jejunum + ileum of anesthetized rats 7-8 and 14-15 (suckling), 21-23 (weanling), 35-36, and 70-73 days old. The amounts of glucose absorbed, expressed as percentage of load perfused (normalized for intestinal weight, milligrams per hour per gram wet weight), were greater in the weanling than in the suckling pups. Rate of glucose absorption increased with increase in glucose concentration in the perfused solutions and reached a plateau when concentration exceeded $3 \mathrm{mg} / \mathrm{ml}$ in the suckling and $10 \mathrm{mg} / \mathrm{ml}$ in the weanling rats. Based on intestinal weight, absorption rates (milligrams per hour per gram wet weight) from solutions containing $10 \mathrm{mg} / \mathrm{ml}$ glucose were 2 times greater in the $21-23$ than in the 7-8-day-old pups (64 versus $30 ; P<0.01$ ). Glucose absorption rates (milligrams per hour per gram wet weight of the perfused intestine) from the $20 \mathrm{mg} / \mathrm{ml}$ solution were similar in the $21-23(64), 35-36(60)$, and $70-73$ (58)-day-old rats. The above results suggested that under the experimental conditions in rats the ability of the small intestine to absorb glucose per unit weight about doubles at the time of weaning as compared with the suckling period with no further enhancement thereafter.

\section{Speculaticn}

In the rat at the time of weaning, intestinal lactase activity decreases, whereas that of sucrase increases. The findings of our study suggest that the same stimulus that increases small intestinal sucrase activity also brings about changes in the glucose transporting mechanism. Other studies showing an increase in rates of glucose absorption in the small intestine under conditions where sucrase activity is enhanced will lend further support to the association between intestinal sucrase activity and glucose absorption rate.

Rate of absorption of 3-O-methyl-D-glucose (a nonmetabolizable hexose) in the small intestine of normal control rats measured during in vivo perfusion was lower in suckling than in weanling rats (15). Although rate of hexose absorption in the intestine of the human infant and adult has not been studied under the same conditions, comparing results of a few infant studies with those in adults suggested that the ability of the jejunum to absorb glucose may be lower in infants than in adults (16). The present study was undertaken to compare rates of $\mathrm{D}$-glucose absorption in the small intestine of the rat at various age periods (between 7 and 73 days after birth). Absorption was measured in vivo using a one-pass perfusion technique under steady state conditions from solutions containing $1-20 \mathrm{mg} / \mathrm{ml} \mathrm{D}$-glucose.

\section{MATERIALS AND METHODS}

All rats studied were obtained from sperm-positive albino
Holtzman mothers (17). On the second day after birth, the pups were randomized among the mothers and litter size adjusted to 7-9 pups and maintained at this number up to the time of weaning (21-23 days). Intestinal absorption was measured in male rats $7-8,14-15,21-23,35-36$, and $70-73$ days old. All animals were fed a regular rat chow (18) ad libitum and allowed free access to water. None were fasted before the intestinal absorption studies. At the time of the study the rats were anesthetized with intraperitoneal injection of an ethylurea-phenobarbital mixture. The 7-8-day-old pups were first anesthetized with ether for $2-3 \mathrm{~min}$, and therafter anesthesia was continued with the solution mentioned above. The details of the methods are described elsewhere (15). After opening the abdominal cavity, an inlet cannula was inserted into the intestinal lumen and tied about $1 \mathrm{~cm}$ distal to the ligament of Treitz. An outlet cannula was similarly placed about $1 \mathrm{~cm}$ proximal to the ileocecal junction. The cannulated jejunum + ileum was washed with $0.9 \%$ sodium chloride solution. The intestine was then inserted back into the abdominal cavity. Body temperature was maintained at $36^{\circ}-$ $37^{\circ}$ at all times. The jejunum + ileum of the $7-8,14-15$, and 21-23-day-old rats were perfused with solutions containing the following concentrations of D-glucose $(19,20): 1,2,3$, $5,10,15$, and $20 \mathrm{mg} / \mathrm{ml}$. For each glucose concentration, a separate group of 4-7 rats was used. All solutions contained $50 \mathrm{mg} / \mathrm{ml}$ phenol red $(20)$ as nonabsorbed indicator for volume change and sodium chloride in sufficient concentration to attain osmolality of $295-300 \mathrm{mOsmol} / \mathrm{liter}$. In each rat the solution was perfused at a constant rate using a peristaltic pump (21). However, in individual rats, the rate of perfusion ranged from $0.20-0.26 \mathrm{ml} / \mathrm{min}$. The perfusates were collected during the following time intervals after the start of the perfusion: $0-30,30-45,45-60,60-75$, and $75-90 \mathrm{~min}$. Glucose and phenol red concentrations were measured in each collected perfusate. Disappearance of glucose from the lumen was taken to mean absorption. Volume change and rate of absorption of D-glucose during the perfusion were calculated using the following formulas: $V_{f}=V_{i} \cdot P R_{i} / P R_{f}$; glucose absorbed, milligrams per $15 \mathrm{~min}=\mathrm{V}_{\mathbf{i}} \cdot[\mathrm{G}]_{\mathbf{i}}-\mathrm{V}_{\mathrm{f}} \cdot[\mathrm{G}]_{\mathrm{f}}$, where $\mathrm{V}$ represents volume (milliters per $15 \mathrm{~min}$ ); $\mathrm{PR}$, phenol red concentration (micrograms per milliter); [G], glucose concentration (milligrams per milliliter); $i$ and $f$, initial and final values in each of the persusates collected. $V_{i}$ is pump rate; $[G]_{i}$, the glucose concentration in the solution before perfusion.

Since rate of absorption of glucose did not vary by more than $10 \%$ during perfusion periods of $30-45,45-60,60-75$, and 75-90 min, the amounts absorbed during these four periods were combined and represented the rate of hexose absorption per hour of perfusion. At the end of the perfusion period, the perfused jejunum + ileum was stripped from the mesentery and divided into two or more $15-25-\mathrm{cm}$ segments, and their length, wet weight, and dry weights determined as described elsewhere $(14,15)$. Rates of absorption of glucose were expressed on the basis of length, wet weight, and dry 
weight of the perfused jejunum + ileum. In the solutions, D-glucose was measured using glucose oxidase $(3,5)$. Phenol red was measured as described by Schedl and Clifton (12). In the older rats, in order to prevent glucose concentrations dropping to very low levels in the solutions during perfusion, the load of glucose perfused through the jejunum + ileum was increased by perfusing the solution at $0.44 \mathrm{ml} / \mathrm{min}$. In the 70-73-day-old rats the segments perfused consisted of about $25 \mathrm{~cm}$ of the jejunum distal to the ligament of Treitz.

\section{RESULTS}

Since body weight and measurements of the perfused jejunum + ileum in the several groups of rats of the same age were similar, data for these groups were combined. The means for the combined values are presented in Table 1. Body weight and intestinal measurements of the rats studied were comparable with those reported previously $(14,15)$. Between 7 and 73 days, intestinal growth involved not only an increase in length, but also a marked increase in its weight to centimeter of length ratio. Water content of the intestine (at the end of the perfusion period) was greater in the older than in the younger pups.

The amounts (load) of glucose perfused through the jejunum + ileum in the 7-23-day-old pups are shown in Table 2 as milligrams per hour and as milligrams per hour normalized for weight of the segments perfused (milligrams per hour per gram wet weight). The amount of glucose absorbed as percentage of load perfused is also shown. As expected from similar loads perfused, the percentage absorption was greater in the jejunum + ileum of the 21-23-day-old rats than either the 14-15-day-old or the 7-8-day-old rats. Even when the loads perfused were normalized for intestinal weight, a greater percentage of the load was absorbed by the 21-23-day-old than by the younger rats.
Figure 1 shows the relationship between rate of $D$ glucose absorption and the concentration of D-glucose in the perfusion solutions for the 7-8, 14-15, and 21-23-dayold rats. Rates of absorption were expressed on the basis of dry weight (Fig. 1a), wet weight (Fig. 1b), and length (Fig. 1c) of the jejunum + ileum perfused. Under the experimental conditions at all three age periods with the increase in glucose concentration in the solutions perfused, the rate of absorption increased up to a point beyond which increments in glucose concentration did not result in further significant rise in absorption rate. In the $7-8$ and $14-15$-day-old rats this concentration was $3 \mathrm{mg} / \mathrm{ml}$ and in the $21-23$-day-old rats it was $10 \mathrm{mg} / \mathrm{ml}$. From solutions containing $10 \mathrm{mg} / \mathrm{ml}$, the rate of glucose absorption was singificantly greater in the $21-23$ day-old than in the 7-8-day or 14-15-day-old rats $(P<0.01)$. At lower glucose concentrations the rates of absorption were similar in jejunum + ileum at the three age periods. At a glucose concentration of $20 \mathrm{mg} / \mathrm{ml}$, the rates of absorption based on jejunal + ileum weight were similar in the 21-23-day, 35-36-day, and 70-73-day-old rats. However, when based on length, rates of absorption were significantly greater in the older than in the younger rats $(P<0.01)$. These higher rates of absorption corresponded to the greater intestinal weight to centimeter of length ratios in older rats (Table 1), which may in part explain the greater rates of absorption based on length of intestine perfused in the older rats.

\section{DISCUSSION}

In our previous study, absorption of 3-O-methyl-D-glucose in the jejunum + ileum of weanling and suckling rats, when normalized for weight of the jejunum + ileum perfused, were 4 times greater in weanling than in suckling rats (15). In these studies absorption was measured from solutions containing two different concentrations of 3-O-methyl-D-glucose. The

Table 1. Age, body weight, and measurements of perfused jejunum + ileum in rats studied

\begin{tabular}{|c|c|c|c|c|c|}
\hline Age (days) & $7-8$ & $14-15$ & $21-23$ & $35-36$ & $70-73$ \\
\hline No. of animals & 25 & 31 & 40 & 7 & 8 \\
\hline Body weight $(\mathrm{g})$ & $18.9 \pm 0.3$ & $35 \pm 5$ & $53 \pm 2$ & $110 \pm 5$ & $299 \pm 10$ \\
\hline Length $(\mathrm{cm})$ & $28 \pm 2$ & $34 \pm 1$ & $51 \pm 1$ & $65 \pm 2$ & $26^{2} \pm 3$ \\
\hline Wet weight (g) & $0.33 \pm 0.01$ & $0.65 \pm 0.04$ & $1.9 \pm 0.1$ & $4.5 \pm 0.3$ & $2.1 \pm 0.4$ \\
\hline Wet weight $(\mathrm{mg} / \mathrm{cm})$ & $12.0 \pm 0.3$ & $18 \pm 1$ & $37 \pm 1$ & $69 \pm 4$ & $76 \pm 4$ \\
\hline
\end{tabular}

${ }^{1}$ Numbers indicate mean $( \pm S E)$ values.

${ }^{2}$ In this group only the proximal jejunum was perfused.

Table 2. D-Glucose load perfused and percentage of load absorbed in jejunum + ileum of suckling and weanling rats ${ }^{1}$

\begin{tabular}{|c|c|c|c|c|c|c|c|c|c|}
\hline \multirow{4}{*}{$\begin{array}{l}\text { D-Glucose concen- } \\
\text { tration in perfused } \\
\text { solutions }\end{array}$} & \multicolumn{6}{|c|}{ Suckling } & \multicolumn{3}{|c|}{ Weanling, $21-23$ days old } \\
\hline & \multicolumn{3}{|c|}{ 7-8 days old } & \multicolumn{3}{|c|}{$14-15$ days old } & & & \multirow[b]{3}{*}{$\begin{array}{l}\text { D-Glucose } \\
\text { absorbed, \% }\end{array}$} \\
\hline & \multicolumn{2}{|c|}{ Load perfused } & \multirow[b]{2}{*}{$\begin{array}{c}\text { D-Glucose } \\
\text { absorbed, \% }\end{array}$} & \multicolumn{2}{|c|}{ Load perfused } & \multirow[b]{2}{*}{$\begin{array}{c}\text { D-Glucose } \\
\text { absorbed, \% }\end{array}$} & \multicolumn{2}{|c|}{ Load perfused } & \\
\hline & $\mathrm{mg} / \mathrm{hr}$ & $\begin{array}{c}\mathrm{mg} / \mathrm{hr} / \mathrm{g} \\
\text { wet wt }\end{array}$ & & $\mathrm{mg} / \mathrm{hr}$ & $\begin{array}{c}\mathrm{mg} / \mathrm{hr} / \mathrm{g} \\
\text { wet wt }\end{array}$ & & $\mathrm{mg} / \mathrm{hr}$ & $\begin{array}{l}\mathrm{mg} / \mathrm{hr} / \mathrm{g} \\
\text { wet wt }\end{array}$ & \\
\hline $1 \mathrm{mg} / \mathrm{ml}$ & 13 & $39 \pm 2$ & $40 \pm 4$ & 13 & $20 \pm 2$ & $69 \pm 6$ & 14 & $7 \pm 1$ & $91 \pm 8$ \\
\hline $2 \mathrm{mg} / \mathrm{ml}$ & 20 & $50 \pm 3$ & $33 \pm 4$ & 25 & $39 \pm 2$ & $62 \pm 4$ & 33 & $17 \pm 1$ & $88 \pm 2$ \\
\hline $3 \mathrm{mg} / \mathrm{ml}$ & 32 & $100 \pm 5$ & $30 \pm 3$ & 43 & $72 \pm 3$ & $50 \pm 6$ & 42 & $27 \pm 2$ & $81 \pm 2$ \\
\hline $5 \mathrm{mg} / \mathrm{ml}$ & 51 & $175 \pm 11$ & $19 \pm 3$ & 57 & $97 \pm 4$ & $38 \pm 5$ & 56 & $41 \pm 2$ & $69 \pm 3$ \\
\hline $10 \mathrm{mg} / \mathrm{ml}$ & 146 & $436 \pm 20$ & $9 \pm 1$ & 140 & $250 \pm 12$ & $18 \pm 3$ & 152 & $93 \pm 4$ & $59 \pm 5$ \\
\hline $15 \mathrm{mg} / \mathrm{ml}$ & & & & & & & 213 & $115 \pm 5$ & $51 \pm 4$ \\
\hline $20 \mathrm{mg} / \mathrm{ml}$ & & & & & & & 283 & $149 \pm 10$ & $43 \pm 5$ \\
\hline
\end{tabular}

\footnotetext{
${ }^{1}$ Numbers indicate mean $( \pm \mathrm{SE})$ values.
} 


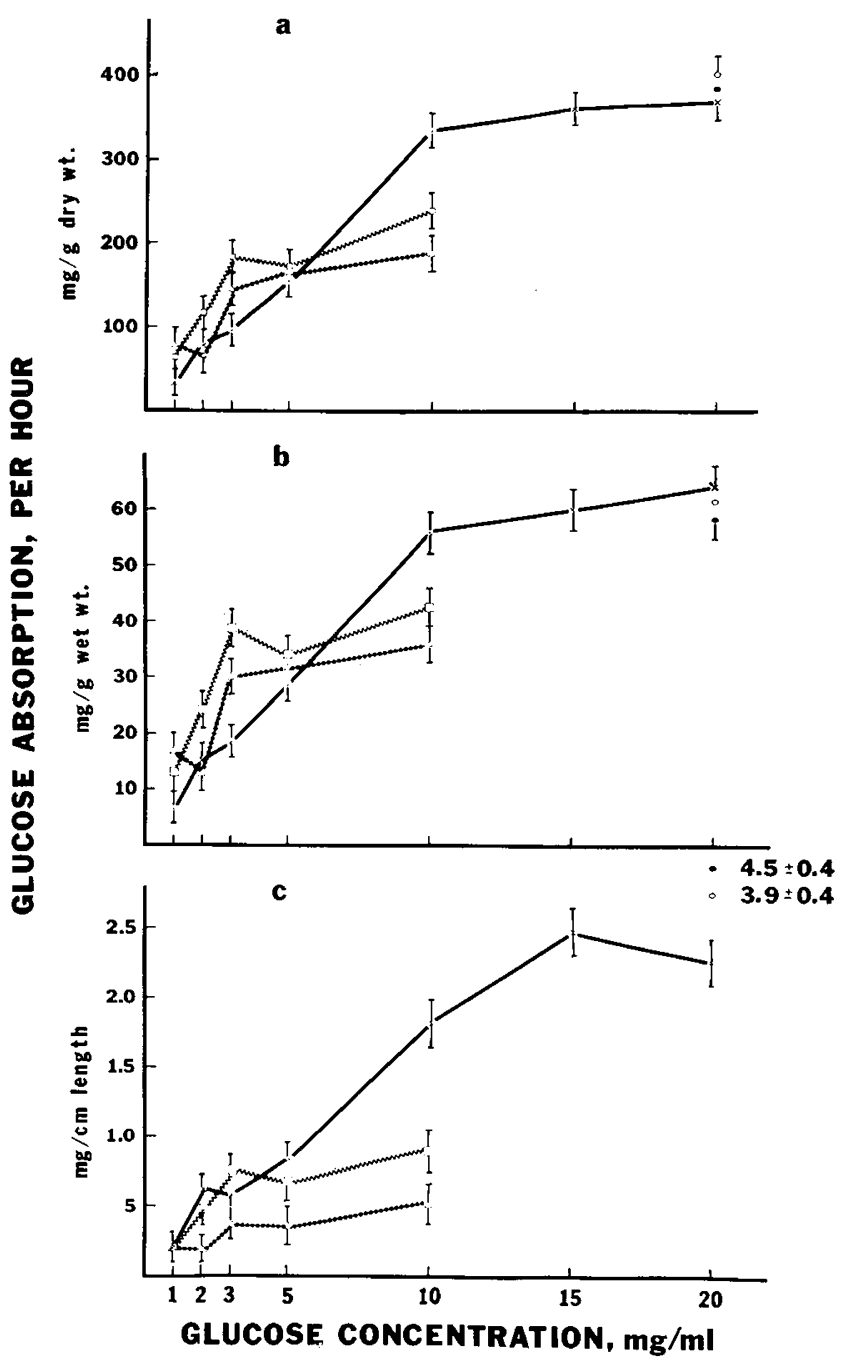

Fig. 1. Rates of absorption of D-glucose during in situ perfusion of the jejunum + ileum in $7-8(\Delta-\Delta), 14-15(\square-\square), 21-23(X-X)$, $35-36(0)$, and $70-73(\bullet)$-day-old rats. The values on the abscissa indicate the initial concentration of D-glucose in the solutions perfused. Mean $( \pm \mathrm{SE})$ rates of absorption indicated by bars are expressed on the basis of dry weight $(a)$, wet weight $(b)$, and length $(c)$ of the perfused jejunum + ileum. Rates of absorption reached a plateau when glucose concentration in the solution perfused exceeded $3 \mathrm{mg} / \mathrm{ml}$ in the $7-8$ and 14-15-day-old pups, and $10 \mathrm{mg} / \mathrm{ml}$ in the $21-23$-day-old pups. $(P$ $<0.01)$. In $c$ rates of absorption in the $35-36$ and $70-73$-day-old pups fall above the scale and are represented numerically.

purpose of the present investigation was to measure and compare the in vivo absorption of glucose in the jejunum + ileum of suckling, weanling, and older rats from solutions containing a relatively wide range of glucose concentrations $(1-20 \mathrm{mg} / \mathrm{ml})$ perfused at a constant rate.

Under the experimental conditions the concentration of glucose in the perfusion solution at which rate of absorption reached a plateau (Fig. 1) was 3 times higher in the $21-23$-day-old than in the suckling rats $(10 \mathrm{mg} / \mathrm{ml}$ versus 3 $\mathrm{mg} / \mathrm{ml}$ ). Above these concentrations, although the load of glucose perfused as milligrams per hour per gram weight of the jejunal + ileal was higher in the suckling rats (Table 1), the percentage of the load absorbed was significantly lower in the suckling rats than in the 21-23-day-old rats (Table 2). From solution containing $10 \mathrm{mg} / \mathrm{ml}$ glucose when absorption rates were at a plateau (Fig. 1), the difference in the amount of glucose absorbed (milligrams per hour) between the 7-8 and 14-15-day-old rats was in proportion to the difference in the weight of their jejunum + ileum. Both were twice as great in 14-15-day-old than in 7-8-day-old rats (Tables 1 and 2).
However, in the 21-23-day-old rats, although weight of the jejunum + ileum was 2.7 times greater than in the 14-15-dayold rats, the amount of glucose absorbed was out of proportion to the difference in weight or about 3.9 times greater in the 21-23-day-old than in the 14-15-day-old rats. The difference between the amount of glucose absorbed in 21-23-day-old and 35-36-day-old rats was in proprotion to the difference in weight of the jejunum + ileum in the two groups. The above findings suggested a change in the manner of glucose absorption by the intestine at the time of weaning allowing more glucose to be transported from the intestinal lumen into the body. The findings of the present study agree quite well with those of our previous study of 3-O-methyl-Dglucose absorption, both showing enhancement in the rate of hexose absorption (milligrams per hour per gram weight) at the time of weaning. The higher rates of glucose absorption in the older than in the suckling rats could have been caused either by a relatively larger number of absorbing villus epithelial cells per unit intestinal weight and/or by an enhancement in the ability of the villus cells to absorb more glucose in the older rats. Inasmuch as the villus epithelial cell number as a percentage of total number of intestinal cells does not change. in albino rats between $14-18$ days and 36-39 days of age (1), it seems unlikely that the rate of absorption (based on intestinal weight) 1.5-fold greater in the 21-23-dayold than in the 14-15-day-old rats (Fig. 1) could have been caused by differences in the relative number of villus epithelial cells. Thus it appeared that the main cause for the rise in rate of glucose absorption at the time of weaning was a change in the glucose-absorbing property of the villus epithelial cells, which allowed more glucose to be transported from the intestinal lumen into the animal. Such a phenomenon could have been restricted only to the proximal intestine. It is possible that before weaning, rate of glucose absorption was similar all along the length of the intestine, but at weaning the ability of the proximal intestine to absorb glucose increased. This would be compatible with the proximal to distal gradient of absorption of glucose noted in adult rats (11).

Because of the marked changes in the luminal concentration of glucose along the length of the intestine during perfusion, kinetic analysis of the data would be hazardous. Similarly the size of the jejunum + ileum perfused varied several fold between the older and younger animals, making comparisons of kinetic data between groups doubtful. Nevertheless, when rates of absorption were plotted against the geometric mean of the initial and final glucose concentrations of the perfusates, both $\mathrm{V}_{\max }$ and $\mathrm{K}_{\mathrm{m}}$ values were lower in the $7-8$ and $14-15$ than in the $21-23$-day-old rats $\left(\mathrm{K}_{\mathrm{m}}: 7-8\right.$ and $14-15$-day-old rats, $7.2 \mathrm{mmol} /$ liter; 21 -23-day-old rats, $16.7 \mathrm{mmol} /$ liter).

Results of some previous in vivo studies of intestinal hexose absorption in the growing rat have been summarized and indicate conflicting findings $(6,7)$. Most used the in vivo methods described by Cori (2) or Verzar (13). In in vivo studies of Heringova and others summarized by Koldovsky (6), rate of D-glucose absorption when based on body weight was considered to be higher in the intestine of 30-day-old than that of younger rats. In older rats, rates of absorption were lower than at 30 days. These findings are not entirely in agreement with the results of the present study, in which rate of absorption based on intestinal weight (Fig. 1) was about equal at $21-22,35-36$, and $70-73$ days of age. Since in the rat small intestinal weight as percent body weight increases from about $2 \%$ at birth to around $5 \%$ by about 30 days of age with a decline in adult life to about $2 \%(4,8,14)$, it is possible that the higher rate of absorption based on body weight in the 30-day-old rats was only a reflection of the relatively larger intestinal mass in the 30-day-old than in the younger or older rats.

Rates of glucose absorption noted in the older rats in this paper are similar to those reported in in vivo studies of other investigators $(9-11)$. For example, Powell and Malawer (9) 
found glucose absorption rate in the proximal intestine to be $12 \mathrm{mmol} / \mathrm{hr} / 10 \mathrm{mg}$ dry weight and in the distal intestine to be $4 \mathrm{mmol} / \mathrm{hr} / 10 \mathrm{mg}$ dry weight. From a similar solution (56 $\mathrm{mM}$ ), the rate of absorption in the present study was approximately $18 \mathrm{mmol} / \mathrm{hr} / 10 \mathrm{mg}$ dry weight of the jejunum + ileum. Rider et al. (11), in perfusion studies of the proximal intestine, found rate of absorption of glucose to be about 10 $\mathrm{mg} / \mathrm{hr} / 10 \mathrm{~cm}$. In the present study, rate of absorption from a solution with a similar mean glucose concentration was 8 $\mathrm{mg} / \mathrm{hr} / 10 \mathrm{~cm}$ of the perfused jejunum + ileum.

\section{SUMMARY}

In vivo study of $\mathrm{D}$-glucose absorption in small intestine of rats between 7 and 73 days of age suggested that rate of absorption normalized for intestinal weight increased twofold at the time of weaning ( $21-23$ days of age) with no further increase thereafter.

\section{REFERENCES AND NOTES}

1. Altmann, G. G., and Enesco, M.: Cell number as a measure of distribution and renewal of epithelial cells in the small intestine of growing and adult rats. Amer. J. Anat., 121: 319-336 (1967).

2. Cori, C. F.: The fate of sugar in the animal body. I. The rate of absorption of hexoses and pentoses from the intestinal tract. $\mathrm{J}$. Biol. Chem., 66: 691-715 (1925).

3. Dahlqvist, A.: Assay of intestinal disaccharidases. Ann. Biochem., 22: 99-107 (1968).

4. Herbst, J. J., and Sunshine, P.: Postnatal development of the small intestine of the rat. Pediat. Res. 3: 27-33 (1969).

5. Huggett, A. St. G., and Nixon, D.: Enzymic determination of blood glucose. Biochem. J., 66: 12P (1957).

6. Koldovsky, O.: Development of Functions of the Small Intestine in Mammals and Man, p. 63. (S. Karger, Basel, 1969).

7. Koldovsky, O.: Hormonal and dietary factors in the development of digestion and absorption. In: $\mathrm{M}$. Winick: Nutrition and

Copyright $\odot 1975$ International Pediatric Research Foundation, Inc.
Development (John Wiley \& Sons, Inc., New York, 1972).

8. Miller, D. L.: Rat small intestine: Development, composition and effects of perfusion. Amer. J. Dig. Dis. 16: 247-254 (1971).

9. Powell, D. W., and Malawer, S. J.: Relationship between water and solute transport from isosmotic solutions by rat intestine in vivo. Amer. J. Physiol., 215: 49-55 (1968).

10. Powell, D. W., Plotkin, G. R., Solberg, L. I., Catlin, D. H, Maenza, R. M., and Formal, S. B.: Experimental diarrhea. II. Glucosestimulated sodium and water transport in rat salmonella enterocolitis. Gastroenterology, 60: 1065-1075 (1971).

11. Rider, A. K., Schedl, H. P., Nokes, G., and Shining, S.: Small intestinal glucose transport. J. Gen. Physiol., 50: 1173-1182 (1967).

12. Schedl, H. P., and Clifton, J. A.: Small intestinal absorption of steroids. Gastroenterology, 41: $491-499$ (1965).

13. Verzar, $F_{.}$, and McDougall, E. J.: Absorption from the Intestine. (Longmans, Green \& Co., London, 1936).

14. Younoszai, M. K., and Ranshaw, J. C.: Gastrointestinal growth in normal male and female rats. Growth, 38: 225-235 (1974).

15. Younoszai, M. K., and Lynch, A.: In vivo intestinal absorption of hexose in growth-retarded suckling rat pups. J. Nutr., 104 . 671-677 (1974).

16. Younoszai, M. K.: Jejunal absorption of hexose in infants and adult. J. Pediat., 85: 446 (1974).

17. Holtzman Co., Madison, Wisc.

18. Wayne Lab Blox, Allied Mills, Chicago, Ill.

19. Paper chromatography showed no contamination by other hexoses or disaccharides. No starch could be detected.

20. Fisher Scientific Co., Fairlawn, N. J.

21. Harvard Apparatus no. 1201, Harvard Apparatus Co., Millis, Mass.

22. Dr. M. K. Younoszai is a recipient of National Institutes of Health Academic Career Development Award AM 70211 in Digestive Diseases-Nutrition.

23. This research was supported in part by Nutrition Foundation Grant no. 451 and Research Grant HD 08227; Department of Child Health and Human Development, National Institutes of Health.

24. Requests for reprints should be addressed to: M. K. Younoszai, M.D., Department of Pediatrics, University of Iowa Hospitals and Clinics, The University of Iowa, Iowa City, Iowa 52242 (USA). 25. Accepted for publication November 12, 1974.

Pediat. Res. 9: 133-138 (1975)

Hypoglycin Jamaican vomiting sickness Reye's syndrome

\title{
Production of the Features of Reye's Syndrome in Rats with 4-Pentenoic Acid
}

\author{
ALLEN M. GLASGOW ${ }^{(35)}$ AND H. PETER CHASE \\ University of Colorado Medical Center, Department of Pediatrics, Denver, Colorado, USA
}

\section{Extract}

4-Pentenoic acid, an analog of hypoglycin which is believed to cause Jamaican vomiting sickness, was administered intraperitoneally to rats in an attempt to produce the features of Reye's syndrome in rats. Mean ammonia levels in plasma were found to be elevated approximately four-fold after injection of $200 \mathrm{mg} / \mathrm{kg}$ pentenoic acid in fed rats. Pentenoic acid caused hypoglycemia in fasted rats and hyperglycemia in fed rats. In chronic experiments rats were injected intraperitoneally every $4 \mathrm{hr}$ with $50 \mathrm{mg} / \mathrm{kg}$ body weight of pentenoic acid for 10 doses, followed by a single dose of $200 \mathrm{mg} / \mathrm{kg}$. The livers of the treated group were enlarged and yellow and showed extensive fatty degeneration. The blood-urea-nitrogen (BUN) was significantly higher and the free fatty acids (FF A's) significantly lower in these rats. This study shows that pentenoic acid administered to rats produces findings similar to those of Reye's syndrome and Jamaican vomiting sickness.

\section{Speculation}

The similarity of the features of Reye's syndrome, Jamaican vomiting sickness, and pentenoic acid and hypoglycin toxicity 